\title{
Risk analysis of the insertion of biofloc technology in a marine shrimp Litopenaeus vannamei production in a farm in Pernambuco, Brazil: A case study
}

\author{
Marcelo Augusto Soares Rego ${ }^{\mathrm{a}, *}$, Omar Jorge Sabbag $^{\mathrm{b}}$, Roberta Soares ${ }^{\mathrm{c}}$, Silvio Peixoto ${ }^{\mathrm{d}}$ \\ a Universidade Federal Rural de Pernambuco, Rua Dom Manoel de Medeiros, s/n, Dois Irmãos, Recife, Pernambuco 52.171-030, Brasil \\ ${ }^{\mathrm{b}}$ Universidade Estadual Paulista Júlio de Mesquita Filho, Av. Brasil Centro, 56, Ilha Solteira, São Paulo 15.385-000, Brasil \\ c Universidade Federal Rural de Pernambuco, Rua Dom Manoel de Medeiros, s/n, Dois Irmãos, Recife, Pernambuco 52.171-030, Brasil \\ ${ }^{d}$ Universidade Federal Rural de Pernambuco, Rua Dom Manoel de Medeiros, s/n, Dois Irmãos, Recife, Pernambuco 52.171-030, Brasil
}

\section{A R T I C L E I N F O}

\section{Article history:}

Received 30 November 2015

Accepted 6 December 2016

Available online 8 December 2016

\section{Keywords:}

Investment analysis

Monte Carlo method

Sensitivity analysis

Biofloc

Shrimp farming

\begin{abstract}
A B S T R A C T
Uncertainties related to the future behavior of projected cash flows cause doubts when choosing investments. Therefore, it is essential to provide information that assist the entrepreneur in decision-making. This study aimed to evaluate the financial indicators and verify the risk of biofloc technology (BFT) and conventional system employed in a shrimp farm in the state of Pernambuco, Brazil. We used the simulation by the Monte Carlo method as a probabilistic analysis of the net present value (NPV) and internal rate of return (IRR). The input variables considered were retail price (US\$/kg), feed price (US\$/kg), labor value (US\$), productivity ( $\mathrm{kg} / \mathrm{ha} / \mathrm{year}$ ), production cycle period (days) and feed conversion rate (FCR). The cash flows have been designed for 10 years to the discount rates of 10,13 and $16 \%$. The BFT system showed greater sensitivity to changes in rates, reducing significantly the NPV when interest rates increased. Risk was only observed in the BFT system, with up to 15\% of probability when subjected to the discount rate of $16 \%$. Both shrimp production systems represent a significant investment alternative for the rural sector in northeastern Brazil, because even from the perspective of risk management, the IRR has $90 \%$ probability of ranging from $7.66 \%$ to $59.40 \%$ for the BFT, and from $67.96 \%$ to $201.03 \%$ for the conventional systems.

Statement of relevance: Brazilian shrimp producers are looking for new technologies to improve their productive performance and to avoid problems related to diseases in conventional pond culture system. They are interested in the biofloc technology (BFT) system, but there are many doubts about financial issues related to this technology. However, few studies evaluate the economic aspects of the different culture systems used in this activity, hampering the decision-making by the producer. Our study verified the viability of the BFT system, as well as the conventional system employed in the northeast Brazilian shrimp farms, but both systems were impacted along the time by productive aspects and changes in the prices of the main inputs used in the production.
\end{abstract}

(c) 2016 Elsevier B.V. All rights reserved.

\section{Introduction}

Brazil is the eighth largest producer of farmed shrimp in the world, with 74,415 tons produced in 2012, being second in Latin America (FAO, 2014). However, the conventional culture of the marine shrimp Litopenaeus vannamei, characterized by using large areas, low stocking densities, poor technological support and constant water flow, is still widely used in Brazil. However, no progress has been observed in the shrimp production in the country in recent years, and many adversities related to the operationalization of the conventional model have been reported (Abreu et al., 2011; Maia et al., 2011).

\footnotetext{
* Corresponding author.

E-mail addresses: mar_soar@yahoo.com.br (M.A.S. Rego), sabbag@agr.feis.unesp.br (O.J. Sabbag), beta.ufrpe@gmail.com (R. Soares), silvio.peixoto@gmail.com (S. Peixoto).
}

Brazilian shrimp producers are becoming interested in closed cultivation systems that are able to withstand higher stocking densities, such as the biofloc technology (BFT) system. They are motivated by the need for development of shrimp farming industry, justified by increases in demand and product selling price, and the constant concern for biosafety (Abreu et al., 2011; Hargreaves, 2006). The BFT system, characterized by the formation of microbial aggregates called bioflocs, is advantageous over the conventional system in relation to their production and biosafety (Avnimelech, 2012; Crab et al., 2012; Hargreaves, 2013).

Investments in production intensification and new technologies contribute to an increased productivity in shrimp farming. However, few studies evaluate the economic aspects of the different culture systems used in this activity, hampering the decision-making by the producer (Muangkeow et al., 2007; Silva et al., 2012; Hanson et al., 2013; 
Gonzalez-Romero et al., 2014). Commonly used techniques to evaluate an investment project and establish parameters of feasibility are the payback period (PP), internal rate of return (IRR) and net present value (NPV). However, are rare in the literature information related to the risks of the various production systems (Bruni et al., 1998).

The impossibility of predicting local and economic conditions related to the project influences the decision-making about the investments, and it is therefore important to consider certain degree of risk and uncertainty. Because it is impossible to get all the important information to implement an activity, it is difficult to eliminate the risk, which is inherent in the project itself. While risk identification is based on the knowledge of the possible future behavior of the main variables that affect the project and their probability of occurrence, uncertainty occurs when the possible future states of these variables are not known (Woiler and Mathias, 1996). We can turn some uncertainties into risk through the simulation process, identifying the future possibilities of the key project variables (Casarotto Filho and Kopittke, 2000).

One of the techniques used for risk analysis is the simulation by the Monte Carlo method, which verifies the probability of each system becoming unviable in the face of operational aspects and price oscillations in the market. By using this method, the probabilistic (stochastic) distribution of the indicator used is generated, determining its probability of standing below an expected value (Costa and Azevedo, 1996).

Even with advantages related to productivity and biosafety, high investments in the BFT system entails uncertainties regarding the acquisition of this technology by entrepreneurs of shrimp farming. These doubts relate mainly to the risks linked to the insertion of this new technology. Considering the need for information that helps entrepreneurs in decision-making, this study aimed to evaluate the financial indicators and check the risk of BFT and conventional systems used in a shrimp farm in northeastern Brazil.

\section{Materials and methods}

The study was conducted in a commercial farm in the state of Pernambuco, Brazil. Information regarding the investment, operating costs and revenues of the BFT system were obtained from the construction and operationalization of three ponds $\left(625 \mathrm{~m}^{2}\right.$ each) covered with high-density polyethylene (HDPE). The data related to the conventional system were obtained from the production history of three semiexcavated ponds ( 2.86 ha each) and from information about the values of new equipment and maintenance of existing structures on the farm. Prices ${ }^{1}$ for the project items and inputs refer to the year 2014.

Both the BFT and the conventional systems were stocked with $\mathrm{PL}_{10}$ (post-larvae with ten days after mysis metamorphosis) of Litopenaeus vannamei from a commercial hatchery. Shrimp of both systems were fed commercial diet (Presence, Camanutri 32\% and 40\% crude protein, São Paulo-Brazil) according to the different stages of their development, with the amount being adjusted after biometrics, and the use of food trays and feed table (Jory et al., 2001).

Sugarcane molasses were used as a carbon source to the formation of bioflocs in the BFT system, maintaining the carbon/nitrogen ratio of 20:1 in the culture medium (Avnimelech, 1999; Ebeling et al., 2006). In order to promote constant aeration, as well as horizontal and vertical movement of the water, a paddlewheel aerator (2 HP) was used in each pond of the BFT system, providing $32 \mathrm{HP}$ per hectare (Hargreaves, 2013). The conventional system did not require mechanical aeration, since it had low stocking densities, and the electricity was used only in water catchment.

For the analysis, we calculated the average of the zootechnical indexes of production obtained during the year 2014, corresponding to 9 and 12 harvests in the BFT and conventional systems, respectively. The zootechnical indexes of production systems used to build the cash flow

\footnotetext{
${ }^{1}$ Reference value (November/2014 - US\$ $\left.1.00=\mathrm{R} \$ 2.49\right)$
}

spreadsheets and risk analysis are shown in Table 1. In order to standardize the comparison between the systems, the area of production considered was 1 ha of waterline, that is, 16 ponds of $625 \mathrm{~m}^{2}$ in BFT and $10,000 \mathrm{~m}^{2}$ in conventional system.

Investment risks in both shrimp farming systems were evaluated by the indicators net present value (NPV) and internal rate of return (IRR). NPV is defined as the sum of the present values of cash flows minus the initial investment value. According to this indicator, the project is only considered viable when the NPV is positive. Discount rates used were 10,13 and $16 \%$ per year, the first one referring to the Special System for Settlement and Custody (SELIC) of 2014, considered the benchmark interest rate of the Brazilian economy, whose value reflects the profitability average of productive activities in the economy (IRSB, 2015).

NPV was calculated according to the following formula:

$\mathrm{NPV}=\left[\sum_{t=0}^{n} \mathrm{PV} /(1+\mathrm{r})^{\mathrm{t}}\right]-\mathrm{I}$

$\mathrm{NPV}=$ net present value; $\mathrm{PV}=$ cash flow value (difference between inflows and outflows); $\mathrm{n}=$ number of flows; $\mathrm{r}=$ discount rate (above savings account opportunity cost); $\mathrm{t}=$ analysis period $(i=1,2,3, \ldots)$; $\mathrm{I}=$ investment value.

From the cash flows for a horizon of 10 years, the internal rate of return (IRR) was determined, by definition, as the indicator that makes the net present value of the flow equal to zero (Noronha, 1981). As criteria for the viability of the project, the IRR must be equal to or greater than the minimum rate of attractiveness (MRA), stipulated in this study to $10 \%$ per year (SELIC). The IRR does not depend on the discount rate chosen, being influenced only by the variation of costs and benefits (Di Trapani et al., 2014). However, this viability indicator shows some weaknesses, as when comparing large and small projects, because it can make small projects appear more attractive, whereas large projects may be more attractive with NPV (Kelleher and MacCormack, 2004).

IRR was obtained according to the following expression:

$0=\left\{\mathrm{FV}_{0}+\left[\mathrm{FV}_{1} /(1+\mathrm{r})^{1}\right]+\left[\mathrm{FV}_{2} /(1+\mathrm{r})^{2}+\left[\mathrm{FV}_{3} /(1+\mathrm{r})^{3}\right]+\ldots+\left[\mathrm{FV}_{\mathrm{n}} /(1+\mathrm{r})^{\mathrm{n}}\right]\right\}-\mathrm{I}\right.$

$\mathrm{FV}=$ net cash flows $(0,1,2,3, \ldots, \mathrm{n}) ; \mathrm{r}=$ discount rate (corresponding to IRR).

To know the importance of each input and each variable on the economic performance of the systems, and then select items with greater influence, we used the sensitivity analysis. All items included in cash flow were checked individually, using a 10\% change in value, always in unfavorable direction for the results of the systems. Thus, it was possible to observe the items with the greatest impact on the indicators of economic viability, NPV and IRR.

The investment project evaluations are frequently linked to the deterministic analysis, simplifying, and often under or overestimating the random behavior of the cash flow information, resulting in uncertainty. Thus, the stochastic assessment through the use of probabilistic models such as the Monte Carlo method is important, because it allows the display of multiple scenarios and their probabilities from random numbers generation, adding relevant information to the process of

Table 1

Means of zootechnical indexes ( \pm standard deviation) for two shrimp production systems (BFT and conventional) evaluated in northeastern Brazil.

\begin{tabular}{lll}
\hline Variables & BFT & Conventional \\
\hline Density (shrimp/m² & $113 \pm 7.2$ & $20 \pm 1.8$ \\
Survival (\%) & $58 \pm 19.6$ & $73 \pm 4.6$ \\
Final mean weight (grams) & $11.9 \pm 3.6$ & $10.4 \pm 0.2$ \\
Productivity (kg/ha/cycle) & $7775 \pm 1955.7$ & $1537 \pm 185.2$ \\
FCR (feed/biomass) & $1.84 \pm 0.3$ & $1.40 \pm 0.1$ \\
Production cycle (days) & $98 \pm 13.2$ & $90 \pm 0.5$ \\
Retail price (US\$/kg) & $5.91 \pm 0.9$ & $5.77 \pm 0.6$ \\
\hline
\end{tabular}


decision-making in risk situations (Sabbag and Costa, 2015; Simões and Gouvea, 2015).

From the results obtained in the sensitivity analysis, we used a simulation technique by Monte Carlo method to assess the risk of the systems. The triangular distribution was adopted for this technique, using the minimum, maximum and mean (most likely) values registered in the system operation for each input (Sabbag and Costa, 2015; Simões and Gouvea, 2015). By using the software SimulAr (version 2.6) in Microsoft Office Excel ${ }^{\circledR}$ platform, 20,000 iterations ${ }^{2}$ were performed among the chosen input variables and different cash flows were generated, from which different results were obtained for the viability indicators (NPV and IRR). After obtaining the frequency distribution of the aforementioned indicators, it was possible to assess the likelihood of success or failure of the system.

The following input variables were used in the simulation by Monte Carlo method, identified in the sensitivity analysis: retail price (US\$/kg), feed price (US\$/kg), labor value (US\$) productivity ( $\mathrm{kg} / \mathrm{ha} /$ year), production cycle period (days) and feed conversion ratio (FCR). To define the variables of price behavior in the region, we estimated the minimum and maximum amount of each financial item input, considering the variation of $10 \%$, less or more, in average values recorded during the year 2014. As for the operational items, the best and worst results recorded in the productions were considered as minimum and maximum for each variable.

In short, the risk analysis was based on the elaboration of scenarios produced by Monte Carlo method. Thus, it was possible to stipulate the range of values (random) to which each variable independently could join, considering their respective defined parameters and distributions.

\section{Results}

For a deterministic assessment, both the BFT and the conventional systems showed positive NPV at predetermined discount rates, confirming their viability even at elevated rates of attractiveness for the activity (Table 2). The BFT system showed greater proportional reduction in the NPV with an increase in the discount rate, which means a greater sensitivity to rising interest rates.

In relation to the results of the probabilistic risk analysis (Monte Carlo method) for each studied production system, only BFT was at risk of becoming unviable (Table 3 ). This probability increased $122 \%$ when the discount rate ranged from $10 \%$ to $16 \%$ per year.

The conventional system had a smaller amplitude in the NPV variation at a discount rate of $10 \%$ (SELIC), ranging from US\$12,421.29 to US\$ $228,830.92$ (Fig. 1). As for the BFT, the NPV ranged from - US\$ $114,828.51$ to US\$ $645,705.62$, proving to be highly impacted by changes in the financial and operational items employed in the Monte Carlo method. The mean values and standard deviations of NPV (10\% per year) obtained on risk analysis were respectively US\$173,963.45 and US\$ $126,794.78$ for the BFT, and US\$ $104,096.39$ and US\$ 36,477.51 for the conventional system, and these results are directly related to the technological level of the system. In this sense, there is a $90 \%$ probability of the NPV (10\% per year) changing between -US\$14,582.73 and US\$ $398,212.85$ with the use of the BFT system, and between US\$ $47,334.94$ and US\$ $167,975.50$ using the conventional system.

The Fig. 1 shows a considerable risk degree considered inherent in the technological standards present in the BFT system, expressed by the probability of $6.8 \%$ of activity failure.

According to the production obtained in 2014, IRR was greater than MRA for both systems, corresponding to $29.44 \%$ in the BFT and $131.86 \%$ in the conventional systems, both being viable. However, when assessing the IRR through Monte Carlo method, the probability of BFT and conventional systems presenting an IRR $<10 \%$ was $6.84 \%$ and

\footnotetext{
2 Number of repetitions.
}

Table 2

NPV (US\$), considering discount rates of 10,13 and $16 \%$ per year, used in two shrimp production systems (BFT and conventional) in northeastern Brazil, in 2014.

\begin{tabular}{llll}
\hline Production systems & \multicolumn{3}{l}{ Discount rate (\%) } \\
\cline { 2 - 4 } & 10 & 13 & 16 \\
\hline BFT & $142,004.42$ & $108,063.14$ & $80,042.74$ \\
Conventional & $105,115.23$ & $91,097.13$ & $79,524.40$ \\
\hline
\end{tabular}

$0.00 \%$, respectively (Fig. 2). The IRR, according to risk analysis, has a $90 \%$ chance to vary between $7.66 \%$ to $59.40 \%$ for the BFT system, and $67.96 \%$ to $201.03 \%$ for the conventional system. The average IRR obtained by Monte Carlo method was equal to $32.60 \%$ in the risk analysis of the BFT system, whereas this indicator was $130.68 \%$ in the conventional system.

\section{Discussion}

The sharp reduction of the NPV in the BFT system by increasing the discount rate is due to the high cost of operation compared to the conventional system, because it uses more inputs by area and skilled labor demand. From this observation, it is concluded that the higher the discount rate, the less attractive will be the BFT system compared to the conventional. Moreover, it is possible to reduce the production cost with an expansion of the system for more appropriate scales (Buarque, 1991; Peres et al., 2004).

The BFT system has presented risks of becoming unviable, with probabilities of $6.80,10.00$ and $15.10 \%$, when subjected to discount rates of 10,13 and $16 \%$, respectively. The conventional system obtained lower return at rates below $16 \%$, although there was no risk of compromising this activity. This fact is attributed to a lower capital expenditure for the purchase of inputs and hiring labor, whose price variation involves high risk (Peres et al., 2004).

Silva et al. (2012) evaluated the economic performance of a conventional system of shrimp farming in the state of Rio Grande do Norte, Brazil. In 2009, the probability of $12.8 \%$ of the NPV ( $12 \%$ of interest) being negative was observed, even with favorable results of the NPV and IRR (US\$ 86,322.86 and 60\%, respectively). However, at that time, the retail price of the shrimp was US\$ $3.13 / \mathrm{kg}$ and the number of cycles/year was 2.5, which explains the occurrence of risk in the scenario presented.

According to Gitman (1997) and Bruni et al. (1998), the risk is directly related to the standard deviation, i.e. with the measure of variability of the returns related to their mean value. The risk involved in the acquisition of an asset is higher with the increase of the standard deviation of the expected value of the returns. The variability of NPV results obtained by Monte Carlo method was higher in the BFT (standard deviation of US\$126,794.78), as well as the risk, corroborating the above noted by those authors.

By analyzing other agricultural activities in Brazil, as milk production in the state of Rio de Janeiro, with projected cash flow for a 20-year horizon, there was a risk of $39 \%$ of the system being unable to remunerate the capital invested at the discount rate of $6 \%$ per year, interest similar to the savings accounts in the period (Haddade et al., 2005). Nonetheless, Peres et al. (2008) observed risks ranging from $4.93 \%$ to $71.69 \%$, at the discount rate of $10 \%$, for different milk production systems in São Paulo state. From these observations, it is possible to associate the risk

Table 3

Probability (\%) of BFT and conventional systems to present negative NPV considering discount rates of 10,13 and 16\% per year in northeastern Brazil, in 2014.

\begin{tabular}{llll}
\hline Production systems & \multicolumn{3}{l}{ Discount rate (\%) } \\
\cline { 2 - 4 } & 10 & 13 & 16 \\
\hline BFT & 6.8 & 10.0 & 15.1 \\
Conventional & 0.0 & 0.0 & 0.0 \\
\hline
\end{tabular}




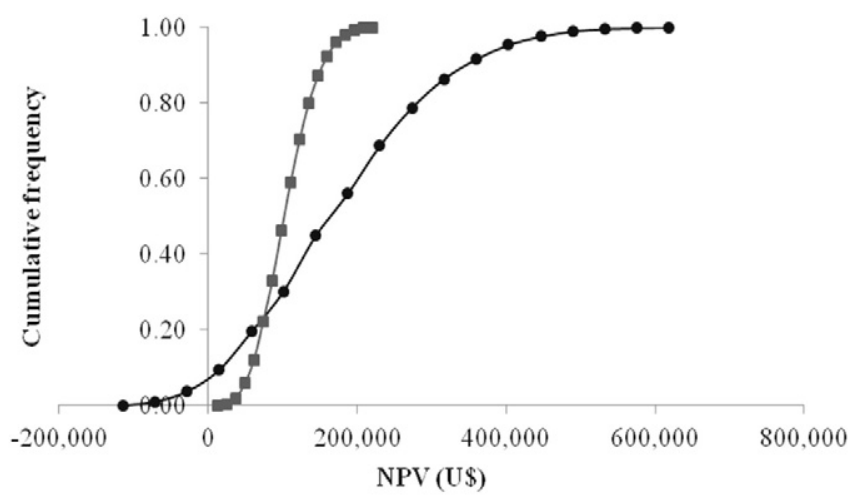

$\rightarrow$ BFT $\rightarrow$ Conventional

Fig. 1. Curves of ascendant cumulative probability of net present value (NPV) simulated by Monte Carlo method for BFT and conventional systems (discount rate of $10 \%$ per year), evaluated in a farm in the state of Pernambuco, Brazil, in 2014.

factors related to the characteristics of each production system, as well as local issues in the area where the activity is likely to be installed.

A high IRR in the conventional system was observed in shrimp farming by Silva and Bezerra (2004), when evaluated an investment in a shrimp farm of 10 ha in the state of Ceará, Brazil, with a 10-year cash flow and IRR equal to $103.65 \%$. The high value of this rate leads to the conclusion that it is preferable to invest in this activity, although there are some problems related to this system incapable of being measured by risk analysis, as the case of the possibility of shrimp contamination by pathogens. Severe disease outbreaks in farmed shrimp have been recorded in many regions of Brazil, being difficult to predict their expansion, as well as the contamination by new pathogens (Costa et al., 2009). Other uncertainties are related to climatic factors, as some production systems are susceptible to the surrounding environment, and disasters might occur, such as the floods recorded in 2008 and 2009 in the state of Rio Grande do Norte, that destroyed 2700 ha of nurseries shrimp farming (Abreu et al., 2011).

Even with risk in the BFT system, the IRR mean results in this study are favorable to both systems evaluated, as they are higher than the remunerations observed in investments available in the market, such as savings accounts with earnings that stood at around $6 \%$ per year over the same period (CBB, 2015). Considering each cash flow obtained through the Monte Carlo method, as a result of a number of risk factors such as prevailing prices and productivity, the rural shrimp farmer will need to improve its business management, bargain prices and improve

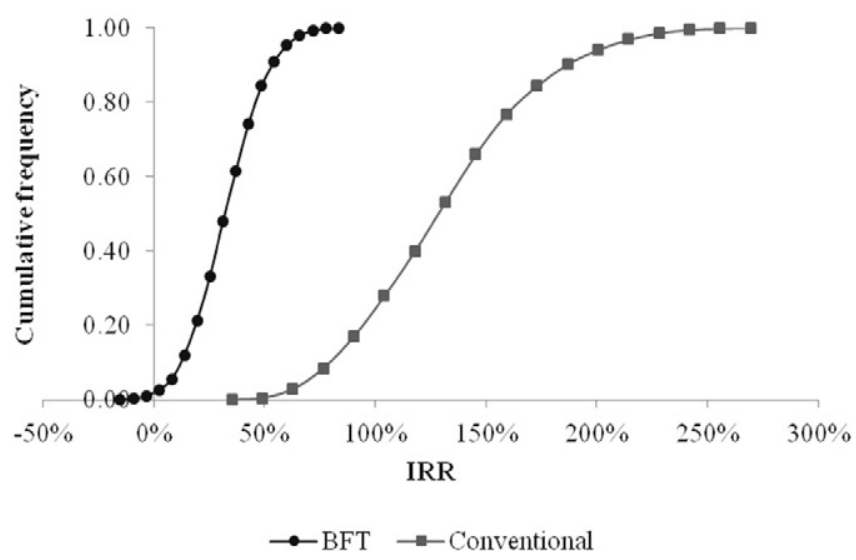

Fig. 2. Curves of ascendant cumulative probability of the internal rate of return (IRR) simulated by Monte Carlo method for the BFT and conventional systems, evaluated in a farm in the state of Pernambuco, Brazil, in 2014. productive management in order to adopt the BFT production system and replace the conventional system.

\section{Conclusion}

Under the different scenarios evaluated in the present study, the BFT culture system of L. vannamei showed risk due to its high sensitivity to changes in costs and revenues in northeast Brazil. However, BFT and conventional systems represent important investment alternatives for the Brazilian rural sector, as they have probability of high financial returns.

\section{Acknowledgements}

The authors would like to acknowledge the National Council for Scientific and Technological Development (Conselho Nacional de Desenvolvimento Científico e Tecnológico - CNPq) for the financial support provided through the grant number 405873/2012-3.

\section{References}

Abreu, M.C.S., Mattos, P., Lima, P.E.S., Padula, A.D., 2011. Shrimp farming in coastal Brazil: reasons for market failure and sustainability challenges. Ocean Coast. Manag. 54 658-667.

Avnimelech, Y., 1999. Carbon/nitrogen ratio as a control element in aquaculture systems. Aquaculture 176, 227-235

Avnimelech, Y., 2012. Biofloc Technology - A Practical Guide Book. second ed. World Aquaculture Society, Baton Rouge, Louisiana.

Bruni, A., Famá, R., Siqueira, J., 1998. Análise do risco na avaliação de projetos de investimento: uma aplicação do método de Monte Carlo. Cad. Pesqui. em Adm. 1 pp. 62-75.

Buarque, C., 1991. Avaliação econômica de projetos. eighth ed. Campus, Rio de Janeiro. Casarotto Filho, N., Kopittke, B.H., 2000. Análise de investimento. Atlas, São Paulo.

CBB (Central Bank of Brazil), 2015. Caderneta de poupança. (From: http://www4.bcb. gov.br/pec/poupanca/poupanca.asp). (Accessed 20 May 2015).

Costa, L.T.A., Azevedo, M.C.L., 1996. Análise Fundamentalista. FGV/EPGE, Rio de Janeiro.

Costa, A.M., Buglione, C.C., Bezerra, F.L., Martins, P.C.C., Barracco, M.A., 2009. Immune assessment of farm-reared Penaeus vannamei shrimp naturally infected by IMNV in NE Brazil. Aquaculture 291, 141-146.

Crab, R., Defoirdt, T., Bossier, P., Verstraete, W., 2012. Biofloc technology in aquaculture: beneficial effects and future challenges. Aquaculture 356-357.

Di Trapani, A.M., Sgroi, F., Testa, R., Tudisca, S., 2014. Economic comparison between offshore and inshore aquaculture production systems of European sea bass in Italy. Aquaculture 434, 334-339.

Ebeling, J.M., Timmons, M.B., Bisogni, J.J., 2006. Engineering analysis of the stoichiometry of photoautotrophic, autotrophic, and heterotrophic removal of ammonia-nitrogen in aquaculture systems. Aquaculture 257, 346-358.

FAO (Food and Agriculture Organization of the United Nations), 2014n. The State of World Fisheries and Aquaculture 2014, Rome.

Gitman, L.J., 1997. Princípios de administração financeira. seventh ed. Harbra, São Paulo.

Gonzalez-Romero, M.A., Hernandez-Llamas, A., Ruiz-Velazcoa, J.M.J., Plascencia-Cuevas, T.N., Nieto-Navarro, J.T., 2014. Stochastic bio-economic optimization of pond size for intensive commercial production of whiteleg shrimp Litopenaeus vannamei. Aquaculture 433, 496-503.

Haddade, I.R., Souza, P.M., Barros, E.E.L., Alves, G.R., Scolforo, L., Cordeiro, M.D., Peras, A.A.C., Henriques, L.T., 2005. Avaliação econômica sob condições de risco em sistema produtivo de gado de leite na região Norte do estado do Rio de Janeiro. Arq. Bras. Med. Vet. e Zootec. 57, 361-366.

Hanson, T., Samocha, T., Morris, T., Advent, B., Magalhães, V., Braga, A., 2013. Economic analyses project rising returns for intensive biofloc shrimp systems. Global Aquac. Advoc. 24-26.

Hargreaves, J.A., 2006. Photosynthetic suspended-growth systems in aquaculture. Aquac. Eng. 34, 344-363.

Hargreaves, J.A., 2013. Biofloc Production Systems for Aquaculture. SRAC Publication, pp. 1-12.

IRSB (Internal Revenue Service of Brazil), 2015. Taxa SELIC. (From: http://idg.receita. fazenda.gov.br/orientacao/tributaria/pagamentos-e-parcelamentos/taxa-de-jurosselic). (Accessed 26 March 2015).

Jory, D.E., Cabrera, T.R., Dugger, D.M., Fegan, D., Lee, P.G., Lawrence, L., Jackson, C.J. Mcintosh, R.P., Castañeda, J., 2001. A global review of shrimp feed management: status and perspectives. In: Browdy, C.L., Jory, D.E. (Eds.), The New Wave, Proceedings of the Special Session on Sustainable Shrimp Culture, Aquaculture 2001. The World Aquaculture Society, Baton Rouge, LA, USA, pp. 104-152.

Kelleher, J.C., MacCormack, J.J., 2004. Internal Rate of Return: A Cautionary Tale. (From: http://www.cfo.com/printable/article.cfm/3304945). (Accessed 19 June 2015).

Maia, E.D.P., Gàlvez, A.O., Brito, L.O., 2011. Brazilian shrimp farms for Litopenaeus vannamei with partial and total recirculation systems species. Int. J. Aqu. Sci 2, 16-27.

Muangkeow, B., Ikejima, K., Powtongsook, S., Yi, Y., 2007. Effects of white shrimp, Litopenaeus vannamei (Boone), and Nile tilapia, Oreochromis niloticus L., stocking 
density on growth, nutrient conversion rate and economic return in integrated closed recirculation system. Aquaculture 269, 363-376.

Noronha, J.F., 1981. Projetos agropecuários: administração financeira, orçamentação e avaliação econômica. Fundação Estudos Agrários Luiz de Queiroz, São Paulo.

Peres, A.A.D., de Souza, P.M., Maldonado, H., da Silva, J.F.C., Soares, C.D., Barros, S.C.W., Haddade, I.R., 2004. Economical analysis of pasture production systems to cattle in the region of Campos dos Goytacazes-RJ. Rev. Bras. Zootec. J. Anim. Sci. 33, $1557-1563$.

Peres, A.A.C., Souza, P.M., Vasquez, H.M., Silva, J.F.C., Carvalho, C.A.B., Carvalho, J.B.P., Morenz, M.J.F., 2008. Análise financeira sob condições de risco de sistemas de produção de leite na região do Vale do Paraíba, SP. 1. Bol. Ind. Ani., pp. 35-42.

Sabbag, O.J., Costa, S.M.A.L., 2015. Análise de custos da produção de leite: aplicação do método de Monte Carlo. Rev. Ext. Rur. 22, 125-145.
Silva, L.A.C., Bezerra, M.A., 2004. Análise econômico-financeira da carcinicultura do estado do Ceará: um estudo de caso. In: XLII Congresso Brasileiro de Economia e Sociologia Rural (Ed.), 2004, Cuiabá, Anais eletrônicos... Cuiabá, 2004. 1 (From: http://sober. org.br/palestra/12/050280.pdf). (Accessed 15 January 2015).

Silva, S.L.G., Pontes, F.S.T., Pontes, F.M., Junior, A.P.B., Oliveira, D.M., 2012. Análise de investimento na carcinicultura do Rio Grande do Norte: um estudo de caso. Rer. Caat. 25, 168-175.

Simões, D., Gouvea, A.C.F., 2015. Método de Monte Carlo aplicado a economicidade do cultivo de tilápia-do-Nilo em tanques-rede. Arch. Zootec. 64, 41-48.

Woiler, S., Mathias, W.F., 1996. Projetos: planejamento, elaboração e análise. Atlas, São Paulo. 